\title{
An In Vitro Assay for Detection of Glomerular Binding IgG Autoantibodies in Patients with Systemic Lupus Erythematosus
}

\author{
Lalbachan Budhai, Kathryn Oh, and Anne Davidson \\ Departments of Medicine and Microbiology and Immunology, Albert Einstein College of Medicine, New York 10461
}

\begin{abstract}
The deposition of anti-dsDNA antibodies in the glomerulus is believed to play a critical role in the pathogenesis of nephritis in SLE. However, an absolute correlation between serum levels of anti-dsDNA antibodies and renal disease has not been found. Recently a glomerular binding assay (GBA) has been developed to detect IgG binding to isolated rat glomeruli. We have used the GBA to study sera from four groups of SLE patients: (A) + anti-dsDNA antibodies, active nephritis; (B) - anti-dsDNA antibodies, active nephritis; (C) + anti-dsDNA antibodies, no nephritis; and (D) - anti-dsDNA antibodies, no nephritis. The serum antids-DNA antibodies in group $A$ and group $C$ patients could not be distinguished on the basis of isotype, charge, or crossreactivity with histones. Nevertheless, the mean intensity of glomerular immunofluorescence was significantly higher in group A than in the three other patient groups and distinguished between patients with serum anti-dsDNA antibodies who had nephritis and those without clinically apparent nephritis. GBA reactivity was unaffected by DNase treatment of sera, but was partially inhibited by preincubation with dsDNA. These findings are consistent with the hypothesis that some anti-dsDNA antibodies cross-react with glomerular components and that the presence of this crossreactivity is associated with, and may be responsible for, the development of nephritis. In addition, we have identified a group of SLE patients with renal disease and typical renal histopathology and immune deposits who do not have serum anti-dsDNA antibodies or antibodies that directly bind to glomeruli in the GBA. The mechanism of renal immune deposition in these patients remains to be determined. $(J$. Clin. Invest. 1996. 98:1585-1593.) Key words: systemic lupus erythematosus - glomerulonephritis - anti-DNA antibodies
\end{abstract}

\section{Introduction}

The nephritis that accompanies SLE is thought to be mediated by immune complexes that deposit in various sites in the kidney and initiate an inflammatory response leading to organ damage or failure (1). The precise specificity of the antibodies

Address correspondence to Anne Davidson, Dept. Rheumatology, Albert Einstein College of Medicine, 1300 Morris Park Ave., U505, Bronx, NY 10461. Phone: 718-430-4107; FAX: 718-430-8789.

Received for publication 22 April 1996 and accepted in revised form 29 July 1996.

J. Clin. Invest.

(C) The American Society for Clinical Investigation, Inc.

0021-9738/96/10/1585/09 \$2.00

Volume 98, Number 7, October 1996, 1585-1593 forming pathogenic immune complexes and the mechanisms by which they deposit in a renal site remain to be fully defined. Antibodies to dsDNA are often found in renal deposits, but the presence of high titers of these autoantibodies in the serum does not always predict renal disease and some patients develop renal disease even though these antibodies are absent from the serum (2). The predominant immunoglobulin isotype deposited in the kidney in SLE patients is IgG, but studies of IgG subclass, relative avidity for dsDNA, and charge have not yielded a common feature that is always associated with nephritogenicity. Molecular studies have shown that these antibodies are heterogeneous, with a tendency towards accumulation of DNA interacting residues, including arginine, in the complementarity determining regions, and that they are likely to be cross-reactive with other polynucleotides, phospholipids, and self proteins (for review see reference 2).

The binding of serum antibodies to isolated rat glomeruli in vitro has been proposed recently as a model system for studying the pathogenesis of SLE nephritis. Studies from Lefkowith and colleagues in MRL mice using this model system have shown that the amount of binding of $\mathrm{IgG}$ to glomeruli correlated better with proteinuria than did serum titers of antibodies to DNA (3). This binding was sensitive to DNase and could be restored by using chromatin bound to collagen type IV on DNase-treated glomerular basement membranes as antigen (4, 5). In the one study that explored the use of this glomerular binding assay (GBA) ${ }^{1}$ in humans, the GBA was a better marker of active renal disease than anti-DNA antibodies, C1q, or anti-C1q (6). However, the effect of DNase on glomerular binding in this study was quite variable, suggesting a more heterogeneous set of binding characteristics in humans than in the MRL mouse.

To further explore the clinical utility of this assay and to begin to examine possible pathogenetic mechanisms of glomerular binding in humans, we have used the GBA to test sera from a large and well-characterized cohort of SLE patients. We have found that for SLE patients with high titers of serum anti-DNA antibodies the GBA distinguishes patients who have renal disease from patients who do not. In contrast, the subgroup of patients with active renal disease in the absence of antibodies to DNA showed little glomerular binding in this assay, suggesting that renal disease in these SLE patients may be mediated by an alternate mechanism.

\section{Methods}

Patients. 190 patients meeting ACR criteria for SLE were prospectively followed in the clinics at Montefiore Hospital and Jacobi Medical Center from December 1993 to August 1995 using an encounter form that records clinical and laboratory data at each visit. Disease activity was assessed using the LAI (7) and MEX-SLEDAI (8) scores based on

1. Abbreviation used in this paper: GBA, glomerular binding assay. 
the encounter forms. Only patients who had complete data collection on at least three occasions were included in this study (132 patients). Active renal disease was diagnosed if the renal score on the LAI visual analogue scale was $>0.5$ (maximum 3 ) and one or more of the follow-

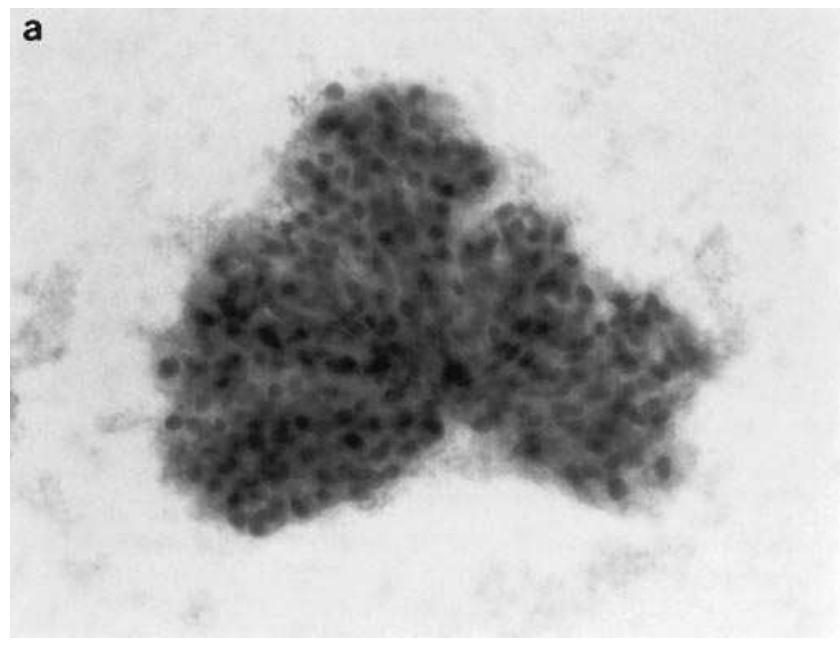

b

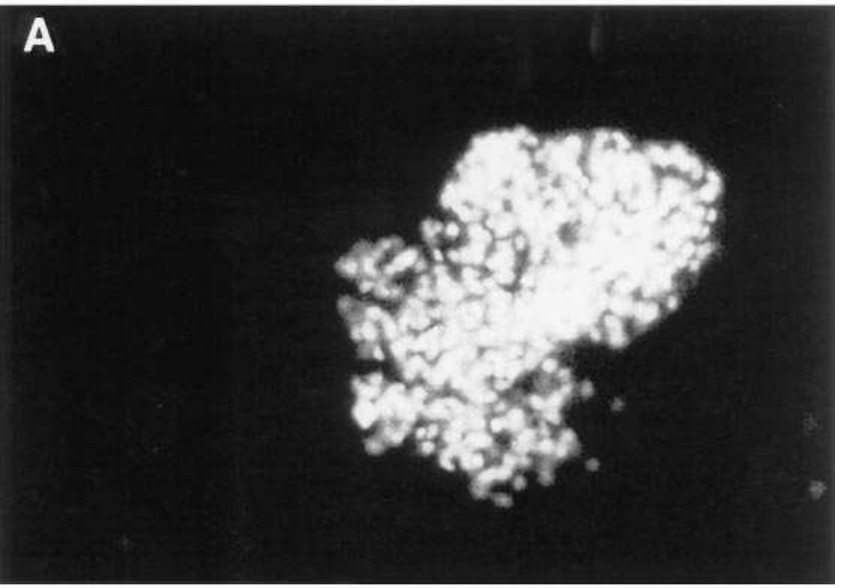

\section{B}

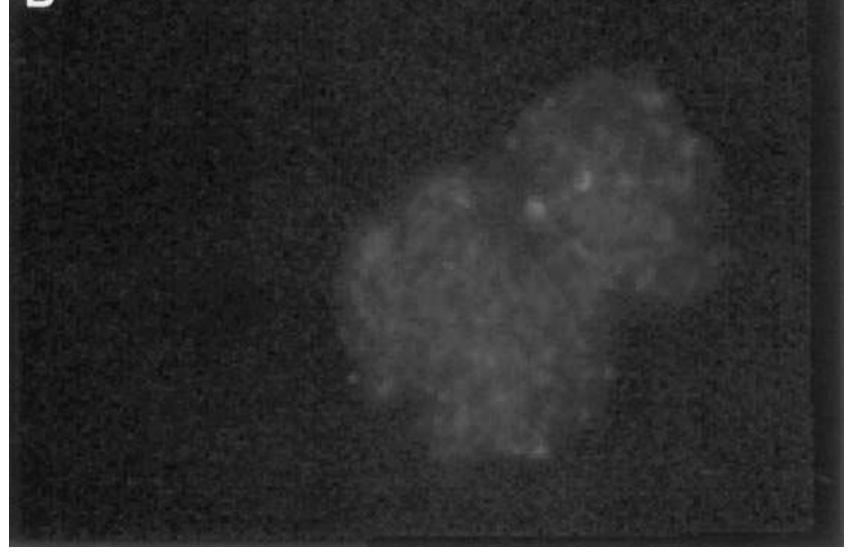

Figure 1. (a) Light microscopy of the rat glomerulus. Hematoxylin and eosin stain of a collagenase- and DNase-treated isolated rat glomerulus. The glomerular architecture appears intact apart from the loss of Bowman's capsule. $\times 40$. (b) DNase-treated glomeruli are devoid of DNA. Propidium iodide stain of a glomerular preparation before $(A)$ and after $(B)$ treatment with DNase. $\times 40$. ing was present: hematuria $>10$ cells/hpf; granular, white cell, or red cell casts; increase in proteinuria $>0.5$ grams $/ 24 \mathrm{~h}$; or, increase in creatinine of $>0.5 \mathrm{mg} / \mathrm{dl}$. In all cases the diagnosis of active renal disease was confirmed by chart review or by direct contact with the patient's physician. One serum sample per patient (representing a time at which active renal disease was present and at which the highest score was recorded on the LAI visual analogue scale) was used for the study. The control groups of patients without past or present renal disease were chosen from among patients seen at least three times during the study period with disease duration $>2 \mathrm{yr}$. Sera from 20 normal individuals were also obtained for use as negative controls. Sera were stored at $-70^{\circ} \mathrm{C}$ and were heat inactivated at $56^{\circ} \mathrm{C}$ for $20 \mathrm{~min}$ before use.

Renal biopsies. Renal biopsies were performed on 12 patients from group A during the course of this study. In addition, pathology reports were obtained for nine study patients from group B, three of whom were biopsied during the course of the study. We were able to obtain retrospective serum samples from the time of biopsy from five of the six group B patients who underwent renal biopsy before the start of the study, and from three additional biopsied patients whose renal disease was inactive during the time of the study.

Serological assays. The amount of IgG in each serum was quantified by ELISA. Plates were coated with $10 \mu \mathrm{g} / \mathrm{ml}$ anti-IgG (BioWhittaker, Inc., Walkersville, MD), blocked with $5 \% \mathrm{FCS} / 3 \% \mathrm{BSA}$ in PBS, and then incubated with serial dilutions of serum. The plates were washed, incubated with peroxidase-conjugated anti-IgG (Accurate Antibodies, Westbury, NY) $1 / 10,000$ in $1 \%$ BSA for $1 \mathrm{~h}$ at $37^{\circ} \mathrm{C}$ followed by ABTS
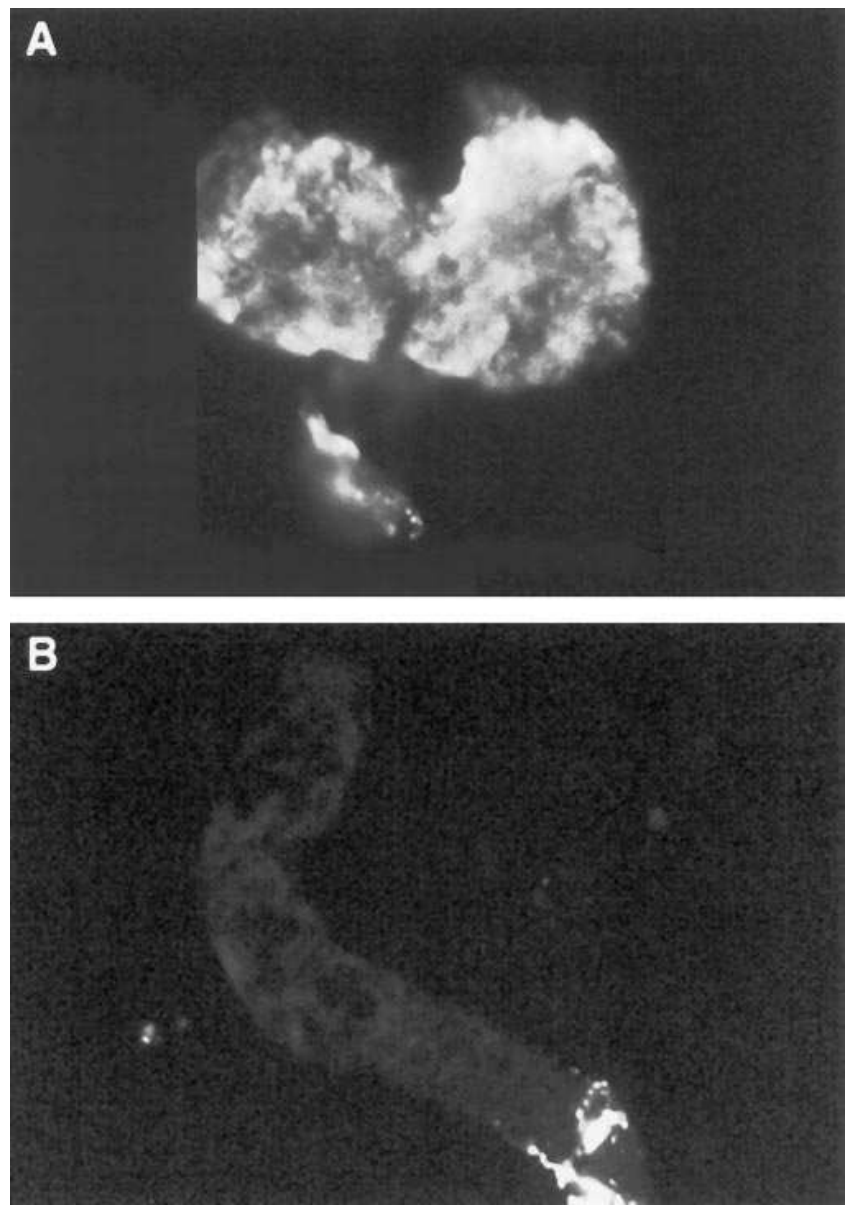

Figure 2. Glomerular staining is specific. Indirect immunofluorescence staining of a glomerular preparation using serum from a patient with SLE. There is intense staining of the glomeruli $(A)$ but no staining of tubular material $(B) . \times 40$. 

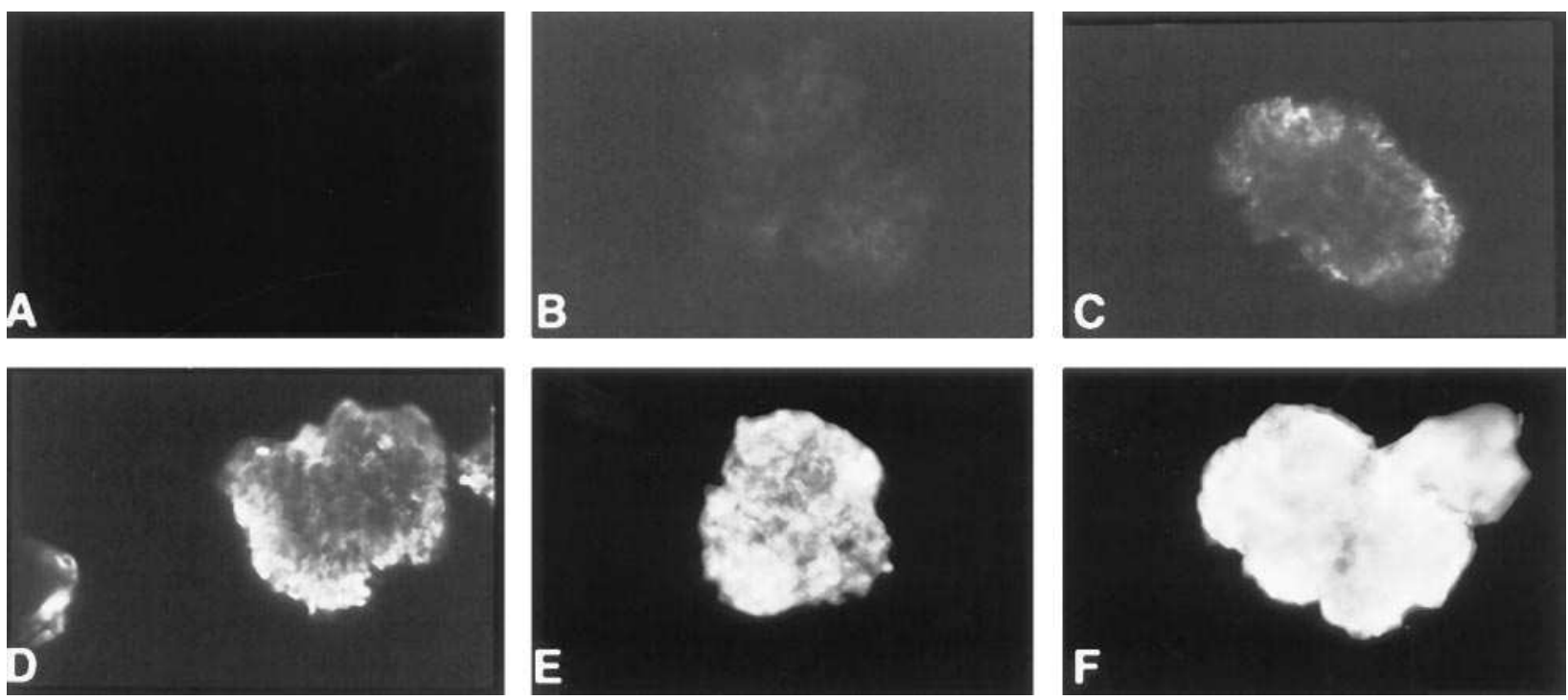

Figure 3. Glomerular staining is graded according to intensity. Immunofluorescence staining of glomeruli with secondary antibody alone $(A, 0$ staining), with control serum ( $B$, trace staining), and with four SLE sera $(C, 1+$ staining; $D, 2+$ staining; $E, 3+$ staining; $F, 4+$ staining). $\times 40$.

substrate. Plates were read on an ELISA reader at $405 \mathrm{~nm}$. Known amounts of normal IgG were used to establish a standard curve.

CH50 tests were performed by our hospital laboratories using commercial kits, and results were obtained from the patients' charts. The values obtained for each patient were scored on a scale of 0 to 3 , where normal ( $>150$ units) was scored as $0,100-150$ units as 1,50 100 units as 2 , and $<50$ units as $3(7)$.

Serum anti-double-stranded DNA antibody levels were determined by the hospital laboratories using a standardized ELISA kit, and results were obtained from the patients' charts. The values obtained for each patient were scored on a scale of 0 to 3 , where a normal result ( $<500$ units) was scored as $0,500-1,000$ units was scored as $1,1,000$ 2,000 units was scored as 2 , and $>2,000$ units was scored as 3 (7).

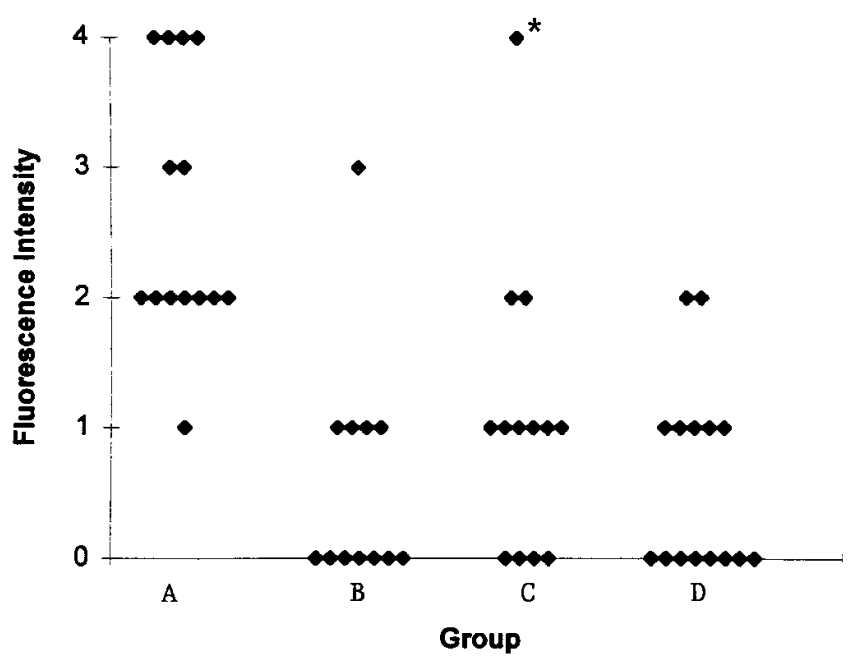

Figure 4. Glomerular staining is most marked in group A patients. Results of the GBA for each of the four groups of SLE patients. Group A patients exhibit significantly more intense immunofluorescent staining than the other three groups $(P<0.0001)$. The GBA result of the patient in group $\mathrm{C}$ who developed proteinuria and an increase in serum creatinine 4 mo after the termination of the study is denoted by the asterisk.
Histone binding assays were performed by ELISA. Histones (Types 1-4, Boehringer Mannheim Corp., Indianapolis, IN) were plated to microtiter wells at $10 \mu \mathrm{g} / \mathrm{ml}$ in PBS. After blocking the wells with FCS/BSA as above, sera were added at 1/500 dilution in PBS/1\% $\mathrm{BSA}$, and incubated for $1 \mathrm{~h}$ at $37^{\circ} \mathrm{C}$. The plates were washed and peroxidase-conjugated anti-human IgG (Accurate Antibodies) 1/10,000 in $\mathrm{PBS} / 1 \% \mathrm{BSA}$ was added at $37^{\circ} \mathrm{C}$ for $1 \mathrm{~h}$, followed by ABTS substrate (Kirkegaard \& Perry Laboratories, Gaithersburg, MD).

Antibody levels to C1q were determined by an ELISA. C1q (human) (Sigma Immunochemicals, St. Louis, MO) was plated to microtiter wells at $10 \mu \mathrm{g} / \mathrm{ml}$ in PBS. After blocking, sera diluted $1 / 100$ in $\mathrm{PBS} / 1 \mathrm{M} \mathrm{NaCl} / 1 \% \mathrm{BSA}$ were added to the plates for $1 \mathrm{~h}$ at $37^{\circ} \mathrm{C}$. The plates were washed and incubated with anti-human IgG as above, followed by ABTS substrate.

IgM rheumatoid factor was measured by an ELISA previously described (9).

Characterization of anti-DNA antibodies. The isotype of serum anti-DNA antibody was determined by an ELISA as follows. Calf thymus DNA (Sigma) was passed through a cellulose acetate filter to ensure double strandedness, plated into microtiter wells at $100 \mu \mathrm{g} / \mathrm{ml}$ in PBS, and allowed to dry overnight in a $37^{\circ} \mathrm{C}$ incubator. The plates were washed and blocked for $1 \mathrm{~h}$ with $5 \% \mathrm{FCS} / 3 \% \mathrm{BSA}$ in PBS and the sera were then added in six sets of duplicates at 1/100 dilution in $\mathrm{PBS} / 1 \% \mathrm{BSA}$ for $1 \mathrm{~h}$ at $37^{\circ} \mathrm{C}$. The plates were washed, peroxidaseconjugated antibodies to human IgM and $\operatorname{IgG}$ (Accurate Antibodies) were added to each of two sets, and mouse monoclonal anti-human $\operatorname{IgG} 1,2,3$, and 4 (Sigma) were added to the other four sets with incubation for $1 \mathrm{~h}$ at $37^{\circ} \mathrm{C}$. The plates were washed and goat anti-mouse peroxidase-conjugated IgG (Accurate Antibodies) 1/20,000 in PBS/ $1 \%$ BSA was added to the four sets containing the anti-IgG subclass antibodies with incubation for $1 \mathrm{~h}$ at $37^{\circ} \mathrm{C}$. The plates were then washed, developed with ABTS substrate, and read.

Isoelectric focusing in $8 \mathrm{M}$ urea was performed on all sera as previously described (10) to determine the charge distribution of the serum anti-DNA antibodies. DNA Western blots were performed to detect anti-DNA antibodies that might be complexed in the serum or of too low affinity to be detected by standard assays (11). $1 \mu \mathrm{l}$ of each serum was electrophoresed on an isoelectric focusing gel in $8 \mathrm{M}$ urea to dissociate immune complexes and the gels were transferred to nitrocellulose filters and probed with radiolabeled double-stranded DNA as previously described (10). In addition, dot blots were performed in which $0.5 \mu \mathrm{l}$ of selected sera was applied to nitrocellulose 
Table I. Patient Characteristics at Test Visit

\begin{tabular}{|c|c|c|c|c|c|c|c|c|c|c|}
\hline Group & No. & F:M & Renal disease & $\begin{array}{c}\text { Mean } \\
\text { anti-DNA (0-3) }\end{array}$ & Mean duration & Low CH50* & $\begin{array}{l}\text { Mean LAI }{ }^{\ddagger} \\
(0-3) \pm 1 \text { SD }\end{array}$ & $\begin{array}{l}\text { No. on } \\
\text { steroids }\end{array}$ & $\begin{array}{l}\text { Mean steroid } \\
\text { dose }^{\S}\end{array}$ & $\begin{array}{c}\text { No. on } \\
\text { cytotoxics }\end{array}$ \\
\hline & & & & & $y r$ & & & & mg prednisone & \\
\hline A & 14 & $13: 1$ & Yes & 2.8 & $7(0.5-18)$ & $11 / 4$ & $1.45 \pm 0.48$ & 13 & $28 \pm 14$ & 10 \\
\hline $\mathrm{B}$ & 12 & $10: 2$ & Yes & 0 & $6(1-14)$ & $6 / 12$ & $1.17 \pm 0.38$ & 12 & $23 \pm 15$ & 12 \\
\hline $\mathrm{C}$ & 14 & 14:0 & No & 2.4 & $10(3-26)$ & $4 / 14$ & $0.75 \pm 0.33$ & 14 & $19 \pm 14$ & 7 \\
\hline $\mathrm{D}$ & 15 & $14: 1$ & No & 0 & $11(2-21)$ & $1 / 5$ & $0.38 \pm 0.21$ & 13 & $12 \pm 9$ & 7 \\
\hline
\end{tabular}

$* P<0.001$ (group A vs. the others); $P=0.06$ (group A vs. group B); $P<0.01$ (group A vs. group C); $P<0.001$ (group A vs. group D). ${ }^{\ddagger} P<0.0001$ (group A vs. the others); $P=\mathrm{NS}$ (group A vs. group B); $P<0.05$ (group A vs. group $\mathrm{C}$ ); $P<0.005$ (group A vs. group D). ${ }^{\S} P<0.02$ (group A vs. the others); $P=$ NS (group A vs. group B); $P=0.07$ (group A vs. group C); $P<0.005$ (group A vs. group D).

membranes that had been preincubated with $10 \mu \mathrm{g} / \mathrm{dot}$ of anti-human IgG and IgM (BioWhittaker) and blocked for $1 \mathrm{~h}$ with $4 \%$ milk. Dot blots were also performed in which $0.5 \mu \mathrm{l}$ of sera, either untreated or treated with $1 \mu \mathrm{l}$ of a 1:10 dilution of $\beta$ mercaptoethanol, was applied directly to nitrocellulose. The membranes were then probed with radiolabeled double-stranded DNA as above.

Isolation of glomeruli. Kidneys were removed from a Lewis rat $>500$ grams (Charles River Laboratories, Wilmington, MA) and sectioned longitudinally. The resulting sections were passed through a 350- $\mu \mathrm{m}$ sieve (Tekto Inc., Briarcliff Manor, NY), collected in a conical tube, and incubated on ice for $10 \mathrm{~min}$ in $1 \mathrm{M} \mathrm{NH}_{4} \mathrm{Cl}$ to lyse red cells. An equal amount of Hanks solution was slowly added to the tube and the mixture was centrifuged for $2 \mathrm{~min}$. The pellet was washed two times using Hanks solution and sieved using a $250-\mu \mathrm{m}$ mesh (Tekto). The resulting pellet was resuspended in a 1:20 dilution of collagenase (type $1 \mathrm{~V}$-S , Sigma, $2 \mathrm{mg} / \mathrm{ml})$ in Leffert buffer $(0.01 \mathrm{M}$ Hepes, $0.003 \mathrm{M} \mathrm{KCl}, 0.13 \mathrm{M} \mathrm{NaCl}, 0.001 \mathrm{M} \mathrm{NaH}_{2} \mathrm{PO}_{4} \cdot \mathrm{H}_{2}, 0.01 \mathrm{M}$ D-glucose, $\mathrm{pH} 7.4$ ) and allowed to incubate for $30 \mathrm{~min}$ at $37^{\circ} \mathrm{C}$. This treatment removes Bowman's capsule (Fig. 1 a) but does not otherwise disturb the glomerular architecture. The pellet was resuspended in Leffert buffer and the glomeruli were allowed to sediment by grav- ity. After several rounds of sedimentation the glomeruli were resuspended at $4 \times 10^{3}$ glomeruli/ml and $5 \mu \mathrm{l}(\sim 20$ glomeruli $)$ was plated out on each slide (Shandon Inc., Pittsburgh, PA). The slides were allowed to air dry, then were fixed in acetone for $5 \mathrm{~min}$, and stored at $-20^{\circ} \mathrm{C}$. Liver cells treated in the same manner were used as a negative control.

$G B A$. Slides containing fixed glomeruli were allowed to thaw $(\sim 1-2 \mathrm{~min})$ and then were washed in PBS $/ 0.05 \%$ Tween for $2 \mathrm{~min}$, followed by a 5 -min incubation in DNase buffer ( $0.01 \mathrm{M}$ Tris, 0.01 $\left.\mathrm{MgCl}_{2}, 0.01 \mathrm{M} \mathrm{CaCl}_{2}, \mathrm{pH} 7.5\right)$. The sections were then incubated twice for $30 \mathrm{~min}$ at $37^{\circ} \mathrm{C}$ using a 1:10 dilution of $1 \mathrm{mg} / \mathrm{ml}$ DNase (Worthington Biochemical Corp., Freehold, NJ). Upon completion of the second incubation, the slides were washed for $5 \mathrm{~min}$ in $1 \mathrm{mM}$ EDTA/ PBS, followed by a 5-min wash with PBS/Tween. Removal of DNA from the glomeruli was confirmed by propidium iodide staining of the glomeruli (Fig. $1 \mathrm{~b}$ ). The sections were blocked for $20 \mathrm{~min}$ using DIFTAG block solution (Shandon Inc.) and then incubated at room temperature for $45 \mathrm{~min}$ with $5 \mu \mathrm{l}$ of serum diluted 1:10 in block solution. Two 5-min washes in PBS/Tween were followed by incubation with FITC-goat anti-human IgG (Shandon Inc.) for $45 \mathrm{~min}$. We chose to stain only with anti-IgG because this has been the immuno-
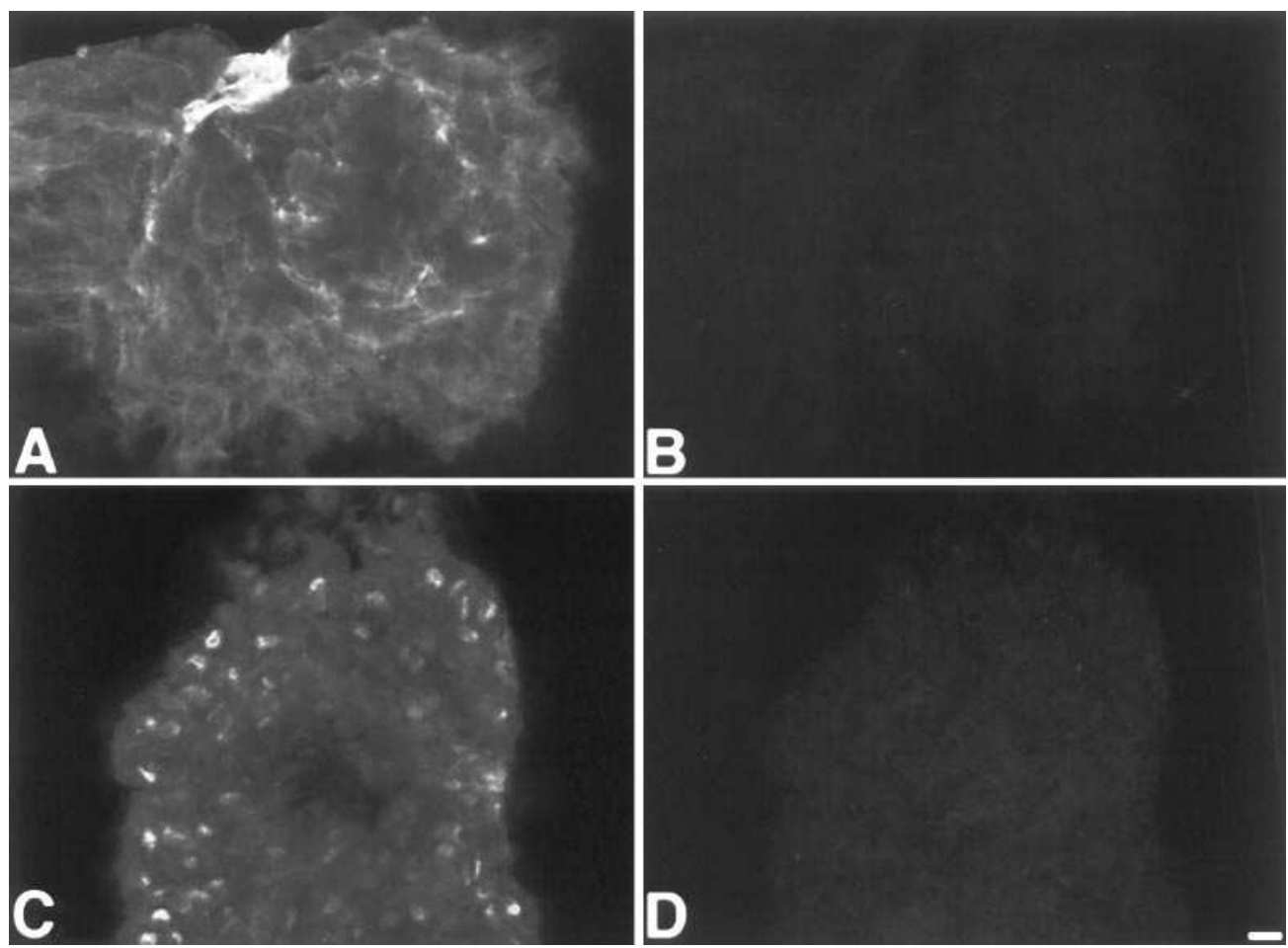

Figure 5. Patterns of glomerular staining are variable. Glomerular immunofluorescence staining exhibited by sera of two SLE patients and examined using confocal microscopy. Two different staining patterns are demonstrated: linear $(A)$ and nuclear $(C)$. Double staining with propidium iodide $(B$ and $D$ ) demonstrates absence of nucleic acid material in the glomerular preparations. $\times 60$. Bar, $10 \mu \mathrm{m}$. 

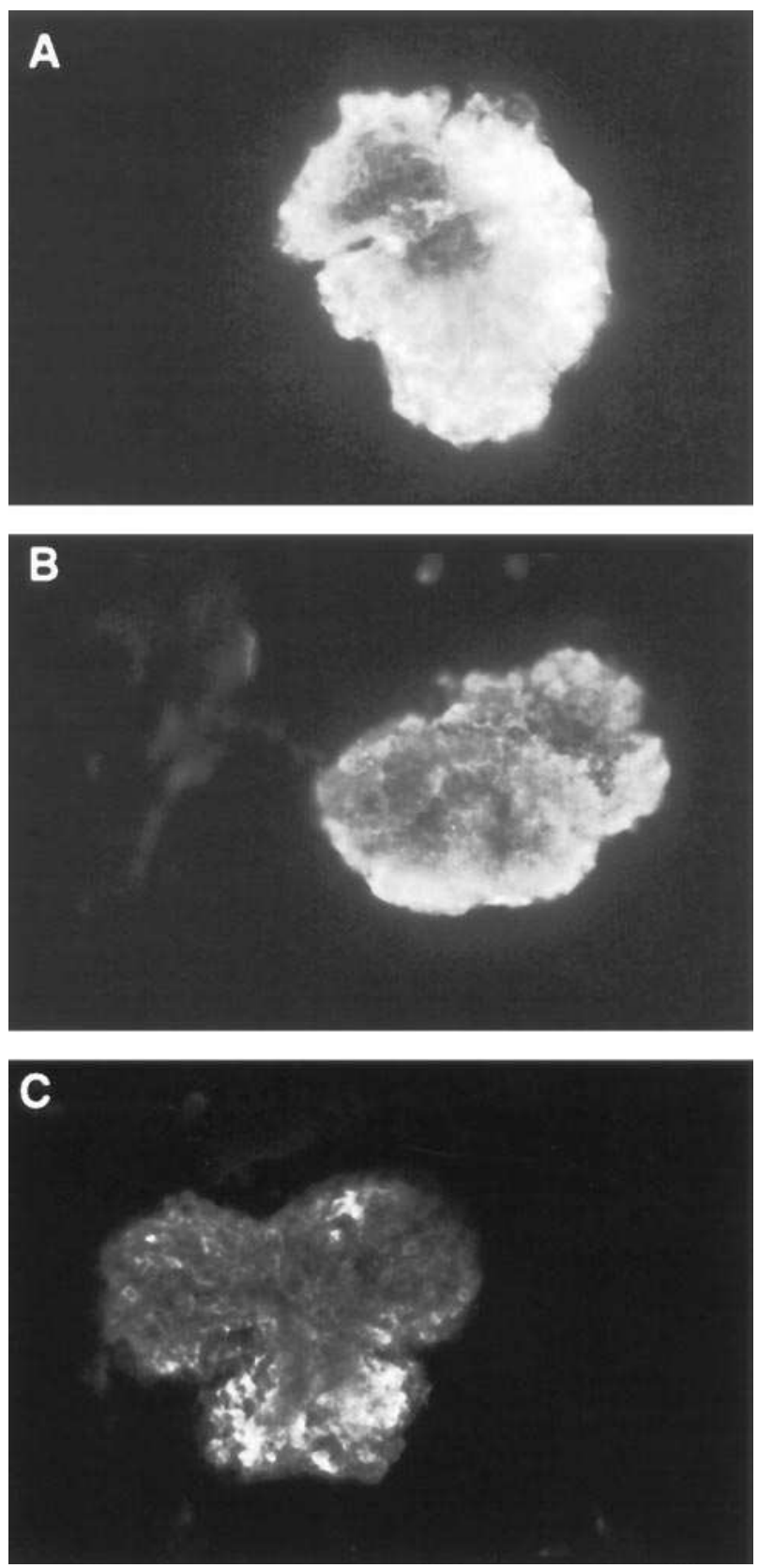

Figure 6. Glomerular staining is inhibited by DNA. Glomerular immunofluorescence staining exhibited by the serum of one SLE patient preincubated with buffer alone $(A), 10 \mu \mathrm{g}$ of dsDNA $(B)$, or 50 $\mu \mathrm{g}$ of dsDNA $(C)$ demonstrates partial inhibition of glomerular binding by dsDNA.

globulin isotype implicated in nephritis, and because clinically, IgM deposits alone are usually associated only with mild or subclinical disease (6). The slides were washed twice for $5 \mathrm{~min}$ in PBS/Tween and mounted using DIFTAG mounting solution. Fluorescence was detected using a ZEISS microscope with an FITC filter. Staining of the glomeruli was generally uniform and specific for glomeruli (Fig. 2). Two representative glomeruli from each slide were photographed and the resulting slides were read blinded at a single session. Fluorescence intensity was graded as $0 /$ trace $1+, 2+, 3+$, or $4+$ as shown in Fig. 3. Each serum was assayed at least twice. Experiments were repeated with selected sera after DNase treatment of the diluted sera (5 $\mu \mathrm{l}$ of a $1 \mathrm{mg} / \mathrm{ml}$ solution of DNase in DNase buffer, added to $50 \mu \mathrm{l}$ of diluted sera), or after preincubation with $50 \mu \mathrm{l}$ of the diluted sera at $37^{\circ} \mathrm{C}$ for $1 \mathrm{~h}$ with 10 and $50 \mu \mathrm{g}$ of dsDNA. This amount of DNA was sufficient to completely inhibit DNA binding in a fluid phase Millipore filter assay but not in the solid phase ELISA. In addition, the pattern of deposition of antibodies was assessed using confocal microscopy.

Statistical analysis. Group comparisons were performed using ANOVA with contrast option for pair-wise group comparison. All tests were two-tailed.

\section{Results}

Patient groups. We identified 26 patients out of 132 who met criteria for the study, who had or developed active renal disease during the 18-mo period from December 1993 to August 1995. The patients were then divided retrospectively into two groups on the basis of serum anti-DNA binding: group A (14 patients) had high titers of anti-dsDNA antibodies and group B (12 patients) had consistently normal levels of anti-DNA antibodies. 14 SLE patients with disease duration $>2 \mathrm{yr}$, no evidence of past or present renal involvement, and a high titer of serum anti-DNA antibodies (i.e., $>1,000$ units) on at least one occasion during the course of the study were designated as group C. 15 patients with disease duration $>2 \mathrm{yr}$, no evidence of renal disease, and consistently normal levels of anti-DNA antibodies were selected as group D on the basis of availability of adequate serum samples.

The demographic data, $\mathrm{CH} 50$ and anti-DNA levels, and disease activity scores at the visit when the GBA tested serum sample was obtained are shown in Table I. The patients with renal disease had significantly lower $\mathrm{CH} 50$ levels and higher disease activity scores than those without kidney involvement irrespective of anti-DNA antibody levels. Hypocomplementemia was present in 17 of the 26 patients with renal disease, but in only 5 of the 29 patients with no evident renal involvement.

GBAs. The GBA results for the four patient groups are shown in Fig. 4. The sera of the patients in group A produced significantly more intense glomerular staining than those in the other three groups $(P<0.0001)$. None of the normal controls exhibited more than trace staining, nor was any staining of liver cells observed (not shown). The amount of staining did not correlate with either the total amount of $\mathrm{IgG}$ in the serum or the titer of serum IgG anti-DNA antibodies (not shown). When the slides were examined by confocal microscopy, staining was seen only in the outside layers of the glomeruli, with penetration to a depth of 5-10 $\mu \mathrm{m}$. Most of the sera produced an extracellular pattern of deposition, but a few exhibited nuclear staining as well; dual staining with FITC-anti-IgG and propidium iodide showed that this was not due to residual DNA in the nuclei (Fig. 5). This pattern of reactivity was unrelated to patient group or to the titer of anti-DNA antibodies (not shown).

Serum pretreatment with DNase or DNA. The five sera that produced the most intense fluorescence in the GBA were pretreated with sufficient DNase to completely digest $10 \mu \mathrm{g}$ of plasmid DNA and the GBA was repeated; the DNase treatment had no effect on the glomerular binding activity of any of these sera (not shown). On the other hand, preincubation of 5 $\mu l$ of the same sera and an additional two sera with 3+ GBA scores, with $50 \mu \mathrm{g}$ of dsDNA, reduced glomerular binding activity by 1 grade in one patient, 2 grades in three patients, and 3 grades in two patients (Fig. 6), indicating that the anti-DNA 


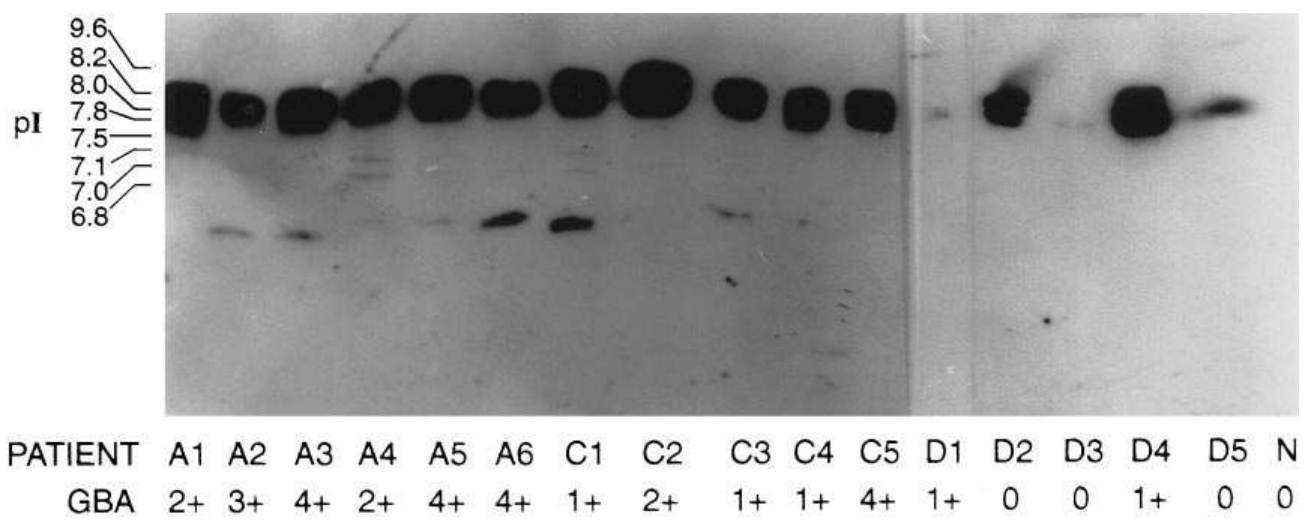

Figure 7. The charge heterogeneity of DNA binding $\mathrm{IgG}$ is similar among all patient groups. Western blot using sera from representative patients from groups $\mathrm{A}, \mathrm{C}$, and D and one normal control, probed with radiolabeled dsDNA. The fluorescence intensity in the GBA is indicated below each patient's designation. activity of these sera was at least partly responsible for glomerular binding. Similarly, dsDNA/anti-dsDNA immune complexes prepared from these sera by immune precipitation showed markedly diminished glomerular binding activity in the GBA compared with the serum from which they were isolated, even when the glomerular substrate had been preincubated with histones (not shown).

DNA Western blots. As expected, the sera of all patients in group A and all but one in group C displayed DNA binding activity by the highly sensitive DNA Western blot assay. The spectrum of activity in both patient groups was in the $\mathrm{pI}$ range of 7-8.5. In addition, the sera of 10 of the 15 group D patients were found to have anti-DNA antibodies using this assay, again in the pI range of 7-8.5. In contrast, binding to DNA was detected in sera of only 4 of the 12 patients in group B and 1 of the 10 normal patients (Fig. 7). That the DNA binding observed was due to Ig was demonstrated by dot blot Westerns in which sera from group B and group D patients who had been negative for DNA binding by standard ELISA, as well as positive and negative controls, were dotted onto nitrocellulose membranes that had been preincubated with anti-human Ig. The blots were then probed with radiolabeled double-stranded

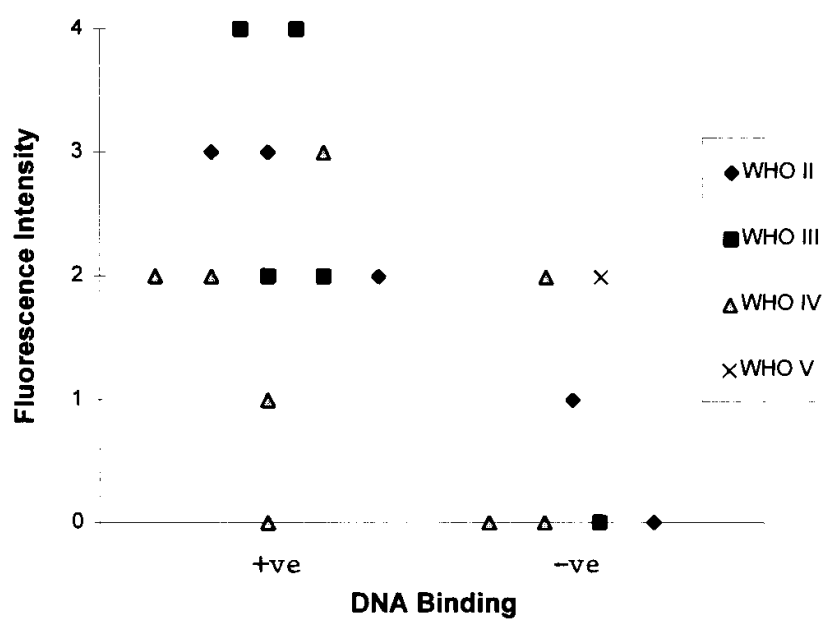

Figure 8. Glomerular binding intensity does not correlate with the histologic grade of the lesion. Glomerular binding activity of sera obtained at the time of renal biopsy from 19 SLE patients. The left side shows patients with DNA binding activity in their sera and the right side shows patients who were negative for DNA binding. The WHO Class of the renal pathology is indicated as shown in the inset.
DNA. In all cases, except for the negative controls, the sera gave a strong signal on the dot blot. Sera bound directly to nitrocellulose also gave a strong signal that diminished to background levels when the sera were first pretreated with $\beta$ mercaptoethanol (not shown).

$G B A$ and renal biopsy findings. Although the intensity of staining in the GBA was higher in the sera of the patients with high titers of anti-DNA antibodies (group A), there was no apparent association of GBA results or anti-DNA titers with the pathological findings on the renal biopsy (Fig. 8). Of the 12 biopsied anti-DNA positive patients, 5 had diffuse proliferative glomerulonephritis, 4 had focal proliferative disease, and $3 \mathrm{had}$ mesangial disease. Seven biopsied patients had absent serum anti-DNA levels at the time of biopsy. Of these, three had diffuse proliferative glomerulonephritis, three had mesangial disease, and one had membranous nephritis. Two patients in group B, one with focal proliferative and one with diffuse proliferative disease, had anti-DNA antibodies detected in the serum sample obtained at the time of biopsy ( $6 \mathrm{yr}$ and 4 mo before the start of the study, respectively), although they continued to manifest features of active renal disease in the absence of these antibodies during the study period. In addition, a patient in group $A$ with a GBA score of $2+$ and a patient in group B with a GBA score of 0 developed significant deterioration of renal function over the course of the study.

Follow-up serum, 6 mo to $6 \mathrm{yr}$ after biopsy, was available in nine patients. Four of these patients had initial GBA scores of $2+$ or more at the time of biopsy that diminished in parallel with anti-DNA antibodies after treatment. Only one patient had a GBA score of $2+$ in the absence of anti-DNA antibodies that diminished with treatment. The remaining four patients

Table II. Antibodies to Histones, C1q, and Fc in the Four Patient Groups

\begin{tabular}{lcccc}
\hline & \multicolumn{4}{c}{ Number of subjects positive } \\
\cline { 2 - 5 } Group & Antihistone & Anti-C1q* & Anti-Fc & GBA $\geq 2$ \\
\hline A (14) & 7 & 5 & 3 & 13 \\
B (12) & 3 & 0 & 2 & 1 \\
C (14) & 9 & 0 & 3 & 3 \\
D (15) & 6 & 0 & 5 & 2 \\
\hline
\end{tabular}

${ }^{*} P<0.05$ (group A vs. group $\mathrm{B}, \mathrm{C}$, or $\mathrm{D}$ ) ${ }^{\ddagger} P<0.0001$ (group A vs. group $\mathrm{B}, \mathrm{C}$, or $\mathrm{D})$. 
had low GBA scores at the time of biopsy which did not change with treatment. These findings suggest that the GBA score is not a marker for the type or severity of the renal lesion in SLE and that it is no better a marker for the type and activity of SLE renal disease than is the anti-DNA antibody titer.

Antibodies to histones, C1q, and Fc. Antibodies with specificities other than for DNA have been associated with renal disease in other studies of SLE (12-14). Therefore, we tested the sera for the presence of antibodies to histones, $\mathrm{IgG}$, and C1q. Antihistone antibodies and rheumatoid factor were found in all patient groups and did not correlate with the presence of active renal disease, serum anti-DNA antibody titers, or GBA scores. However, five patients, all in group A, demonstrated high titers of antibodies to $\mathrm{Clq}(>3 \mathrm{SD}$ above the mean of 20 normal controls). These data are summarized in Table II.

\section{Discussion}

Renal involvement in SLE is believed to be a consequence of the deposition of immunoglobulin in the kidney (1). Three mechanisms have been suggested to explain how this may occur. The first is that circulating preformed immune complexes, consisting predominantly of DNA and antibodies to DNA, are trapped in the glomeruli $(15,16)$. Both renal and skin lesions in SLE patients have DNA/anti-DNA deposits (17), but only a few of the many investigators who have tried have been able to identify such immune complexes in the circulation of SLE patients (15), and there are no good animal models for renal pathogenicity of preformed immune complexes.

A second mechanism for renal deposition of anti-DNA antibodies, proposed by Termaat and colleagues (14) on the basis of studies using an in vivo perfusion system, is that anti-DNA antibodies bind to complexes of DNA and histone that have deposited in glomerular basement membrane or in collagencontaining structures present in the mesangial matrix. Studies in MRL mice by Lefkowith et al. (3-5), using the in vitro GBA which was the model for the GBA we have used here, support this mechanism. These investigators found that glomerular binding was inhibited by treatment of MRL mouse serum or glomerular basement membrane with DNase (3), and that the binding of a panel of monoclonal DNA and histone binding antibodies derived from MRL mice could be restored by the addition of DNA and histone to DNase-treated glomerular basement membrane or duplicated by reacting anti-DNA or antihistone antibodies with type IV collagen coated with DNA and histone $(4,5)$. Lefkowith et al. also found that in vitro glomerular binding by MRL mouse sera was distinct from serum anti-DNA binding and correlated better with proteinuria, particularly in treated mice (3). However, it is unclear from these studies whether all anti-DNA antibodies are able to bind to a preformed chromatin-like glomerular complex, or whether all the antibodies that bind to this substrate are nephritogenic. A recent in vivo study comparing three monoclonal anti-DNA antibodies derived from MRL mice has identified a pathogenic anti-ssDNA antibody whose only distinguishing feature is that it binds in vitro to a DNase sensitive epitope in renal sections (18).

The third proposed mechanism for the renal deposition of anti-DNA antibodies is that these antibodies cross-react with and directly bind to glomerular antigens other than DNA. The glomerular membrane is a complex structure whose major components include type IV collagen, laminin, fibronectin, and proteoglycans (19). There is substantial evidence that not all anti-DNA antibodies are nephritogenic and suggestive data implying that nephritogenicity of human anti-DNA antibodies is due to a subset of anti-DNA antibodies that is cross-reactive with glomerular components. Raz et al. (20) have shown that perfusion of rat kidney with polyclonal anti-DNA antibodies derived from patients with SLE nephritis resulted in antibody binding to glomeruli. No antibody binding was observed when perfusion was performed with anti-DNA antibodies from nonnephritic SLE patients (20). These findings are consistent with the results of the in vitro assay as presented here. Other investigators have demonstrated that anti-DNA antibodies eluted from kidney deposits, but not circulating anti-DNA antibodies, cross-react with glomerular membrane antigens. Preincubation of the glomerular eluates with glomerular basement membrane antigens inhibited anti-DNA reactivity, but absorption with DNA did not completely absorb out anti-glomerular basement membrane reactivity (15). Madaio and colleagues characterized a mouse monoclonal anti-DNA antibody that also reacted with laminin and deposited directly in the mesangial and subendothelial regions of the kidney (21). In addition, they studied a panel of cross-reactive anti-DNA antibodies and found that their cross-reactivity profiles varied, that only some deposited in the kidney despite high serum levels, and that patterns of kidney immunofluorescence varied. They suggested that the different cross-reactive binding patterns might influence the nature and outcome of the renal lesion (22). The variety of antibody binding patterns that we found using confocal microscopy, with some SLE sera binding only outside the cells and others binding to both cellular and extracellular components, is similarly consistent with the heterogeneity of human glomerular binding antibodies.

Lefkowith and colleagues have also reported their findings in a study of in vitro glomerular binding activity of sera of SLE patients (6). In vitro glomerular binding was detected in the sera of 9 of 15 nephritic SLE patients compared with only 5 of 45 inactive or nonnephritic SLE patients. There was no apparent correlation between anti-DNA, GBA, and sensitivity of GBA to DNase treatment of the sera. Only 4 of the 15 sera from nephritic patients had elevated levels of anti-DNA antibodies; all of these sera had elevated GBA, but only two were substantially inhibited by DNase treatment (6).

In the present study, a GBA based on that of Lefkowith et al. (3) using a DNA-depleted glomerular substrate was applied to a larger and better characterized cohort of SLE patients grouped on the basis of presence or absence of nephritis and an elevated level of serum anti-DNA antibodies. High levels of GBA activity occurred almost exclusively in the SLE patients with nephritis and elevated anti-DNA antibody levels (group A). The GBA activity in these patients was uniformly unaffected by DNase treatment of the serum, but was inhibited by high concentrations of DNA, suggesting that the GBA was due in part to anti-DNA activity but also represented binding to an antigen other than DNA. There was no correlation between GBA and antihistone reactivity, contrary to what might be expected if histone-DNA complexes were the glomerular substrate for GBA as postulated by Termaat and colleagues (14). These findings are more consistent with the evidence cited (20-22) above in favor of glomerular binding of antiDNA antibodies being due to cross-reactivity with one or more inherent glomerular basement membrane components. 
Glomerular binding in the GBA appears to be associated with SLE nephritis; 13 of the 14 SLE patients with elevated anti-DNA levels and nephritis (group A) had high GBA scores compared with only 3 of the 14 patients with high antiDNA and no nephritis (group C). Improvement of renal disease with treatment in 5/6 of the group A patients was accompanied by a fall in GBA score. Over the course of this study one patient with $4+$ GBA, originally assigned to group $\mathrm{C}$, developed an increase in proteinuria and an active urinary sediment and a second, with 4+ GBA, who had been treated with high dose corticosteroids and azathioprine for active CNS disease and severe arthritis and had been without evidence of renal disease for $>5 \mathrm{yr}$, experienced a rise in serum creatinine from 0.8 to $1.4 \mathrm{mg} \%$ and the new finding of $400 \mathrm{mg} / 24 \mathrm{~h}$ proteinuria 4 mo after the end of the study period.

Because the same rat glomerular substrate was used for all the experiments, the GBA-associated difference in the antiDNA antibodies of the patients in groups $\mathrm{A}$ and $\mathrm{C}$ is likely to be due to a qualitative difference in the anti-DNA antibodies themselves rather than any difference in the patients' kidneys. We did not find any substantial difference in antibody titer, isotype, or charge of the circulating anti-DNA antibodies with or without high GBA score or renal disease, so that the identity of the factor that promotes anti-DNA nephritogenicity and whether it involves cross-reactivity with a glomerular component remain to be elucidated.

The pathogenesis of renal disease in the SLE patients without detectable serum anti-DNA antibodies (group B) is also of considerable interest. These patients were clinically similar to those in group A, with statistically insignificant differences in their LAI scores and steroid dosage. However, the GBA score in these patients was not significantly different from that of the patients with no renal disease, being greater than $2+$ in only one instance. Renal biopsy findings that included immunofluorescence studies were available for five of these patients; pathologic changes and immunoglobulin deposits typical of SLE were found in all cases and were indistinguishable from those biopsied patients from group A. Marked hypocomplementemia was present in $4 / 5$ of these group B patients at the time of biopsy. Thus, renal disease in the patients without elevated serum anti-DNA antibody levels appears to involve immune deposition and complement activation very much like the patients with anti-DNA antibodies. There are several possible explanations for this. First, the nephritis in group B patients may be due to renal deposition of anti-DNA antibodies, but levels in their sera may be too low to detect by conventional clinical assays. Using a sensitive Western blot assay for anti-DNA binding, we found only two group B patients with strong binding and two with weak binding to dsDNA. Second, the antibodies in the sera of group B patients may bind to a glomerular antigen present in human kidney but not in the rat glomerular substrate used in the GBA assay. Finally, renal damage in some or all group B patients may be mediated by antibodies that do not react or cross-react with DNA; in this regard, it is notable that a significant proportion of antibodies eluted from kidneys of patients with SLE are not anti-DNA antibodies (2).

The clinical utility of the GBA used here is likely to be a limited one. GBA levels appear to reflect changes in disease activity in group A patients, but the GBA is no better in this respect than anti-DNA levels. Our biopsy findings further suggest that the GBA is not a marker for the histological severity of renal lesions. However, the GBA test does distinguish group A patients from group $C$ patients and may be useful in identifying the SLE patients with serum anti-DNA antibodies who are likely to develop nephritis. The GBA may be more valuable as an in vitro tool for elucidating the pathogenesis of lupus nephritis, allowing identification of the mechanism of immune deposition and the nature of the glomerular substrate that may be involved.

\section{Acknowledgments}

The authors wish to thank Mr. Luis Delavega and Mr. Leonid Strizhevskiy for technical assistance, Dr. Peter Barland for retrospective sera, Dr. C.J. Chang for statistical analysis, Mr. Michael Cammer of the Analytic Imaging Facility for confocal microscopy, and Dr. Betty Diamond and Dr. Harold Keiser for critical review of the manuscript.

This work was supported by National Institute of Arthritis and Musculoskeletal and Skin Diseases grant RO1 AR 42481-03.

\section{References}

1. Golbus, J., and W.J. McCune. 1994. Lupus nephritis. Rheum. Dis. Clin. N. Am. 20:213-242.

2. Foster, M., B. Cizman, and M. Madaio. 1993. Nephritogenic autoantibodies in SLE: immunochemical properties, mechanisms of immune deposition and genetic origins. Lab. Invest. 69:494-507.

3. Bernstein, K.A., D. Bolshoun, and J.B. Lefkowith. 1993. Serum glomerular binding activity is highly correlated with renal disease in MRL/lpr mice. Clin. Exp. Immunol. 94:418-423.

4. Bernstein, K.A., R. DiValerio, and J.B. Lefkowith. 1995. Glomerular binding activity in MRL lpr serum consists of antibodies that bind to a DNA/ Histone/Type IV collagen complex. J. Immunol. 154:2424-2433.

5. DiValerio, R., K.A. Bernstein, E. Varghese, and J.B. Lefkowith. 1995. Murine lupus glomerulotropic monoclonal antibodies exhibit differing specificities but bind via a common mechanism. J. Immunol. 155:2258-2268.

6. Bernstein, K.A., L.E. Kahl, J.E. Balow, and J.B. Lefkowith. 1994. Serologic markers of lupus nephritis in patients: use of tissue-based ELISA and evidence for immunopathogenic heterogeneity. Clin. Exp. Immunol. 98:60-65.

7. Petri, M., M. Genovese, E. Engle, and M. Hochberg. 1991. Definition, incidence, and clinical description of flare in systemic lupus erythematosus. Arthritis Rheum. 34:937-944.

8. Guzman, J., M.H. Cardiel, A. Arce-Salinas, J. Sanchez-Guerrero, and D. Alarcon-Segovia. 1992. Measurement of disease activity in systemic lupus erythematosus. Prospective validation of 3 clinical indices. J. Rheumatol. 19: 1551-1558.

9. Davidson, A., J. Lopez, D. Prus, and D. Sun. 1992. A monoclonal antiidiotype specific for human polyclonal IgM rheumatoid factor. J. Immunol. 148: 3873-3878.

10. Halpern, R., A. Davidson, A. Lazo, G. Solomon, R. Lahita, and B. Diamond. 1985. Familial SLE. Presence of a cross-reactive idiotype in healthy family members. J. Clin. Invest. 96:731-736.

11. Halpern, R., J. Sciffenbauer, G. Solomon, and B. Diamond. 1984. Detection of masked anti-DNA antibodies in lupus sera by a monoclonal anti-idiotype. J. Immunol. 133:1852-1856.

12. Miyazaki, M., M. Endoh, T. Suga, N. Yano, T. Kuramoto, T. Matsumoto, K. Eguchi, M. Yagame, M. Miura, Y. Nomoto, and H. Sakai. 1990. Rheumatoid factors and glomerulonephritis. Clin. Exp. Immunol. 81:250-255.

13. Siegert, C., M. Daha, C. Tseng, I. Coremans, L. van Es, and F. Breedveld. 1993. Predictive value of IgG autoantibodies against C1q for nephritis in SLE. Ann. Rheum. Dis. 52:851-856.

14. Termaat, R.M., K.J.M. Assmann, H. Dijkman, F. van Gompel, R. Smeenk, and J. Berden. 1992. Anti-DNA antibodies can bind to the glomerulus via two distinct mechanisms. Kidney Int. 42:1363-1371.

15. Sasaki, T., T. Muryoi, A. Hatakeyama, M. Suzuki, H. Sato, J. Seino, and K. Yoshinaga. 1992. Circulating anti-DNA immune complexes in active lupus nephritis. Am. J. Med. 91:355-362.

16. Sasaki, T., A. Hatakeyama, S. Shibata, H. Osaki, M. Suzuki, K. Horie, Y. Kitagawa, and K. Yoshinaga. 1991. Heterogeneity of immune complexderived anti-DNA antibodies associated with lupus nephritis. Kidney Int. 39: 746-753.

17. Isenberg, D.A., and D. Collins. 1985. Detection of a cross-reactive antiDNA antibody idiotype on renal tissue-bound immunoglobulins from lupus patients. J. Clin. Invest. 76:287-294.

18. Bruijin, J. 1994. The glomerular basement membrane in lupus nephritis. Microsc. Res. Techn. 28:178-192. 
19. Swanson, P.C., R.L. Yung, N.B. Blatt, M.A. Eagan, J.M. Norris, B.C. Richardson, K.J. Johnson, and G.D. Glick. 1996. Ligand recognition by murine anti-DNA antibodies. J. Clin. Invest. 97:1748-1760.

20. Raz, E., M. Brezis, E. Rosenmann, and D. Eilat. 1989. Anti-DNA antibodies bind directly to renal antigens and induce kidney dysfunction in the isolated perfused rat kidney. J. Immunol. 142:3076-3082.
21. Madaio, M.P., J. Carlson, J. Cataldo, A. Ucci, P. Migliorini, and O. Pankewycz. 1987. Murine monoclonal anti-DNA antibodies bind to glomerular antigens and form immune deposits. J. Immunol. 138:2883-2889.

22. Vlahakos, D., M. Foster, S. Adams, M. Katz, A. Ucci, K. Barrett, S Datta, and M. Madaio. 1992. Anti-DNA antibodies form immune deposits at distinct glomerular and vascular sites. Kidney Int. 41:1690-1700. 